\title{
Amyotrofik Lateral Sklerozda Semptom Yönetimine Genel Bakış
}

\author{
Overview of Symptom Management in Amyotrophic Lateral Sclerosis \\ Duygu AKBAŞ ${ }^{1}$ A,B,C,D,E,F® , Ayfer KARADAKOVAN ${ }^{2}$ A,B,C,D,E,F,G \\ ${ }^{1}$ S.B.Ü. Bozyaka Eğitim ve Araştırma Hastanesi, Yanık Tedavi Merkezi, İzmir, Türkiye \\ ${ }^{2}$ Ege Üniversitesi Hemşirelik Fakültesi, İç Hastalıkları Hemşireliği Ana Bilim Dalı, İzmir, Türkiye
}

$\ddot{O Z Z}$

\begin{abstract}
Amyotrofik Lateral Skleroz (ALS), ortalama 2-5 y1l sağkalım gösteren ilerleyici bir motor nöron hastalığıdır. Uygulanan tedaviler sadece hastalığın ilerlemesini yavaşlatmaya yardımcı olmaktadır. Tedavideki bu eksiklikten dolayı ALS'nin kliniklerde multidisipliner semptom temelli yönetimi, hasta için en önemli güncel tedavi stratejisi olmaya devam etmektedir. $\mathrm{Bu}$ anlamda hemşireler ALS'nin klinik yönetiminde ekibin faaliyetlerini kontrol etmede, tedaviyi kolaylaştırmada, aile üyelerine bilinçli bakım uygulamalarında rehberlik etmede ve yaşam sonu destek aşamasında kritik bir rol oynar.
\end{abstract}

Anahtar Kelimeler: Amyotrofik lateral skleroz, semptom, semptom yönetimi, hemşirelik.

\section{ABSTRACT}

Amyotrophic Lateral Sclerosis (ALS) is a progressive motor neuron disease with an average survival of 2-5 years. The treatments applied only help slow the progression of the disease. Due to this deficiency in treatment, multidisciplinary symptom-based management of ALS in clinics continues to be the most important current treatment strategy for the patient. In this sense, nurses play a critical role in the clinical management of ALS in controlling the team's activities, facilitating treatment, guiding family members in conscious care practices, and in the end-of-life support phase.

Key Words: Amyotrophic lateral sclerosis, symptom, symptom management, nursing.

\section{GíRiş}

Motor nöron hastalığı olarak da bilinen Amyotrofik Lateral Skleroz ( ALS ) ilk olarak 19. yüzyılda Fransız nörolog Jean-Martin Charcot tarafından tanımlanmıştır(1). Dünya üzerinde ALS prevelans1 3-8/100.000, y1ll1k insidans1 ise 1-2/100.000 olarak bildirilmektedir(1). Ülkemizde ise veriler kesin değildir (1-2).

Amyotrofik Lateral Sklerozun \% 90-95'1 tesadüfi (sporadik), \% 3-10’u ailesel (familyal) olarak görülmektedir(3). Yapılan çalışmalarda ALS ile ilgili 25 tane gen bulunmuştur (3). Ailesel olguların \% 20'sinde, sporadik olguların ise \% 1-5'inde 21. kromozom üzerindeki $\mathrm{CuZn}$, Superoksid Dismutaz (SOD1) enziminin kodlandığı gen üzerinde mutasyon bulunmaktadır(3). Genetiğin aksine, ALS için çevresel risk faktörlerinin tanımlanması daha zordur(4). Sigara içmek bazı çalışmalarda artmış ALS riski ile ilişkilendirilmiştir(4). Ağır metaller, ortam aromatik hidrokarbonlar, böcek ilaçları ve siyano toksinler gibi kimyasalların riskli olduğuna dair karışık kanıtlar vardır (4). Yapılan bir meta-analiz çalışmasında kafa 
travmasının risk faktörü olduğu görülmüştür (4). Yapılan bazı çalışmalar, orduda görev yapan kişilerin ALS riskinin daha yüksek olduğunu göstermektedir (3-5).

ALS'li hastalarda hayatta kalma süresi 2 ila 5 yıl arasındadır $(1,2)$. Bu kötü prognoza rağmen hastaların \%20'si 5 yıl, \%10'u 10 yıl, \%5'i 20 yıl veya daha uzun yaşamaktadır. Semptomların ortalama başlangıç yaşı 55'tir $(3,4)$. ALS tanısı semptomlarının başlamasından yaklaşık 9 ila 12 ay içerisinde konulur (2-5). Tanıdaki bu gecikme hastalara erken tedavide zorluk çıkartmaktadır. Hastalarda ALS belirtilerinin görülmeye başlanması aslında motor nöronlarının yaklaşık\% 50 ila\% 70'inin kaybedildiğinin göstergesidir (2).

\section{Klinik Belirti ve Bulgular}

Amyotrofik Lateral Skleroz beyindeki ve omurilikteki motor nöronları etkileyen ilerleyici bir nörodejeneratif bozukluktur (6-7). Nöronlarda görülen bu ilerleyici kayıp iki farklı ALS semptomu olarak ortaya çıkmaktadır (6). Spinal başlangıçlı hastalarda ekstremitelerde belirgin bir güç azalması görülürken, bulbar başlangıçlı hastalarda yutma güçlüğü en önemli semptomdur (6-7). Semptomlar tipik olarak bir ekstremitede güçsüzlük olarak kendini gösterir; ancak, vakaların üçte birinde dizartri, disfaji ve solunum fonksiyon bozukluğu ile sonuçlanan bir bulbar prezentasyonu vardır (7).

Amyotrofik Lateral Sklerozdaki diğer yaygın semptomlar yorgunluk ve azalmış egzersiz kapasitesidir. Hastalık ilerledikçe hastalar temel günlük aktiviteler için yardıma ihtiyaç duyarlar (6-8). ALS de görülen semptomlardan biri de bilişsel bozulmadır (7). ALS'li hastaların \%15 inde frontotemporal demans, kişilik değişikliği ve sinirlilik görülmektedir (4).ALS sadece motor nöronları etkilediği için görme, dokunma, işitme, tat ve koku alma duyusu etkilenmez. Çoğu ALS hastasının göz kasları etkilenmemiştir (7).

ALS hastalarında fasiyal sinir tutulumu sebebiyle, yüz ifadesi ile birlikte kaş hareketleri, IX, XII. kraniyal sinirlerin tutulumu sebebiyle konuşma, yutma, trigeminal sinir tutulumu sebebiyle de çiğneme fonksiyonu kaybedilir (6-8).

ALS semptomları ayrica birincil ve ikincil semptomlar olarak ayrılabilir (6-8). Birincil semptomlar arasında kas güçsüzlüğü, atrofi, spastisite, konuşma bozuklukları, oral sekresyonların kontrolünde güçlük, yutma güçlüğü ve ölümle sonuçlanan solunum komplikasyonları bulunur (6-8). İkincil semptomlar genellikle birincil semptomlara eşlik ederler; ağrı ve beraberinde günlük aktivitelerin yerine getirilememesiyle yaşam kalitesini önemli ölçüde azaltırlar (6-8).

\section{Hastalık Yönetimi}

Günümüzde ALS tedavisinde kullanılan Amerikan Gıda ve İlaç Dairesi (FDA) tarafından onaylanmış iki tane ilaç vardır (9).

İlk olarak FDA tarafından onaylanan tedavi, glutamaterjik bir nörotransmisyon inhibitörü olan riluzoldür. Riluzol (Rilutek), uyarıcı nörotransmitter glutamat salınımı üzerinde engelleyici bir etki yoluyla motor nöronlara verilen hasarı azaltır (9). Klinik çalışmalarda, ALS'li hastaların trakeostomi veya ölümüne kadar geçen ortalama süreyi 2 ila 3 ay uzattığ saptanmıştır (9). 
"Radicava (Edaravone)", Mayıs 2017'de ALS'yi tedavi etmek için onaylanan diğer ilaç olmuştur. Radicava, sinir hücrelerine oksidatif stres hasarını önleyerek nöroprotektif bir ajan olarak işlev görür (9).

\section{Amyotrofik Lateral Skleroz'da Semptom Kontrolü}

Mehta ve ark (2017) yaptıkları çalışmada bir ALS'li hasta hastalık deneyimini şöyle ifade etmiştir: "Daha kısa yaşam beklentisine sahip olan ALS hastaları, yaşam deneyimlerini ve ilişkilerini daha derin hale getirirler. Herkesin tekerlekli sandalyesi olduğu ve hiç kimsenin hayatın krizlerinden sonsuza dek kaçınmadığı kavramını anlamak faydalı olacaktır" (4). Bu alıntı ALS hastalarının yaşadığı mücadeleyi göstermektedir ALS'nin zorluklarını kabul etmek zorunda olmasına rağmen, potansiyellerini en üst düzeye çıkarmaları gerektiğini göstermektedir (4). Bu anlamda ALS'li hastalara destek olmak ve semptom yönetimi konusunda yardımcı olmak için etkili bir hemşirelik bakımına ihtiyaç duyulmaktadır.

\section{Siyalore}

Siyalore, ALS'de solunum yetmezliği dışındaki en yaygın ölüm nedeni olan aspirasyon pnömonisine yol açabilen faringeal kas güçsüzlüğü ile ilgili bir semptomdur (10). ALS hastalarında siyalorenin prevalansının \%50 olduğu tahmin edilmektedir (10). Hastalar sık sık ağızlarını bir mendille silmek zorunda kalırlar veya salgının arttığı durumlarda tükürüğü emmek için ağızlarına bir kağıt havlu veya bez koyarlar (10).

Siyalore için kabul edilen birinci basamak farmakolojik tedavi seçeneği antikolinerjik ilaçlardır. Günümüzde yeni uygulanan ve geleneksel tıbbi tedaviye dirençli hastalarda büyük umut vaat eden tedavi şekli ise botulinum toksinidir (10-11).

Hastada görülen koyu ve yapışkan salgılar hasta için büyük bir sorun oluşturur. $\mathrm{Bu}$ salgılar sadece tükürük bezlerinden kaynaklanmayabilir, aynı zamanda burun ve ağız mukozası da salgıları artırabilir. Hastada görülen bu yapışkan sekresyonlar su kaybının bir belirtisi olabilir. Hemşirelerin sıvı alımını artırması konusunda hastayı desteklemesi gerekir (12-13).

Ayrıca ağız içinde oluşabilecek zararlı bakteri üretimini azaltmak için hastalar düzenli ağız bakımı yapmaya teşvik edilmelidir (11).

\section{Uyku Bozukluğu}

Amyortofik Lateral Skleroz'lu hastalarda görülen uyku bozukluğunun nedenleri, kas güçsüzlügüne bağlı pozisyon değiştirmedeki zorluklardan, aşırı sekresyonlardan, anksiyete depresyondan kaynaklanabilir $(11,12)$. Gece görülen hipoventilasyon toplam uyku süresinin azalmasına neden olarak gündüz yorgunluğuna ve düşük konsantrasyona neden olur $(11,12)$. Genel olarak, bozulmuş uyku hastaların yaşam kalitesini olumsuz yönde etkilemektedir (12).

Uyku kalitesini artırmak için hemşirelerin üreteceği çözümler oldukça çeşitlidir. Klinikte alternatif basınçlı hava yatağı veya jel kaplama yatak kullanılarak sınırlı hareket kabiliyetinden kaynaklanan rahatsızlık azaltabilir (12). Noninvaziv pozitif basınçlı ventilasyon, solunumu önemli ölçüde rahatlatır ve hastaların uyku kalitesini artırmaya yardımcı olur (12). 


\section{Solunum Fonksiyonlarında Değişim}

Amyotrofik Lateral Skleroz hastalarında diyafragmatik ve interkostal kas gücünde azalma ve glottis fonksiyonunda bozulma sonucu solunum yetmezliği görülür $(12,13)$. Dispne, ALS de kronik solunum yetmezliğinin nadir görülen bir belirtisidir. Aksine, hastalar genellikle sık sık gece uyanmaları, sabah baş ağrısı, gündüz aşırı uykulu olma, ortopne ve yorgunluk gibi noktürnal oksijen desatürasyonları ile ilgili semptomlarla başvurmaktadırlar $(12,13)$.Hastalar bulbar semptomları ilerledikçe seslerinde (hacim ve ton) değişiklikler, sekresyonları temizlemede güçlük, zayıf öksürük ve yutma güçlügü yaşayabilirler. Hastalara kontrollü bir şekilde solunum egzersizleri yaptırılarak öksürüğün etkinliğinin artırılması sağlanır. Yatakta veya sandalyede pozisyonları ayarlanır.

Hastalarda gerektiğinde iki seviyeli pozitif hava yolu basınç (BIPAP) ya da sürekli pozitif hava yolu basıncı (CPAP) olarak adlandırılan noninvaziv (NIV) pozitif basınçlı ventilasyon cihazları kullanılabilir (12,13). Solunum yetersizliğinin başlangıç evresinde hastanın solunumuna destek olmak amacı ile NIV kullanılır (14). Hemşirelerin NIV uygulaması yaparken, hasta konforunu en üst düzeye çıkarmak ve bası yaralarını en aza indirmek için burun maskesi, burun yastıkları veya tam yüz maskesi gibi cihazları tercih etmesi gerekmektedir. NIV, bol sekresyonlu, bilişsel bozukluğu veya bakıcı desteği eksikliği olan hastalarda kontrendikedir. $\mathrm{Bu}$ nedenle hemşirelerin NIV tedavisi alan hastaları dikkatle takip etmesi gerekir (14).

Amyotrofik Lateral Skleroz hastalarında her 3-6 ayda bir solunum fonksiyon değerlendirmesi yapılmalıdır. Ekspiratuar solunum kas güçsüzlügü etkisiz öksürüğe, üst hava yolu salgılarına ve pulmoner enfeksiyonlara yol açabilir(14).Salgıların kolay mobilizasyonunu sağlamak için yeterli hidrasyon sağlanmalıdır $(13,14)$.Önemli nöromüsküler hastalığı olan tüm hastaların yılda bir veya daha fazla doz pnömokok aşısının ve ilgili grip virüsü için yıllık aşılarının yapılması önerilmektedir $(13,14)$. Hastalar aşılanma konusunda bilgilendirilmelidir.

\section{Beslenmede Değişim}

Amyotrofik Lateral Skleroz hastalarında disfaji, kas atrofisi, depresyona bağlı iştahsızlık ve hipermetabolik durum nedeniyle kilo kaybı ortaya çıkabilir (15-16). Semptom başlangıcından tanıya kadar \%10'dan fazla kilo kaybının olması ve beden kütle indeksinin hızlı değişimi progonuzu olumsuz etkilemektedir (16).

Yemek saatlerinde görülen öksürük ve boğulma hissi orofaringeal ve dil güçsüzlüğünün belirtileridir $(15,16)$. Disfaji, ALS'de aspirasyona ve yetersiz beslenmeye yol açarak prognozu olumsuz yönde etkileyebilir. Bu nedenle etkili bir hemşirelik değerlendirmesi yapılmalıdır. Hemşireler, hastanın sıvı ve katı gıdaları yutma yeteneğini değerlendirmelidir $(15,16)$. Hastalarda nöromüsküler disfajinin gelişmesiyle birlikte sıvı gıdaların alımı zorlaşır $(15,16)$. $\mathrm{Bu}$ nedenle, hastalara hastalığın erken evrelerinde bile daha koyu sıvılar (meyve nektarı vb.) alması gerektiği veya ticari olarak temin edilebilen koyulaştırıcıların sıvı gıdalara eklenmesi gerektiği bilgisi verilmelidir. Hastalar, güvenli yutma eylemini gerçekleştirebilmek için kuru veya ufalanan yiyecekler yerine yumuşak ve nemli yiyecekleri tercih etmeleri konusunda bilgilendirilmelidir $(15,16)$.

Beden kütle indeksinin normal sınırlarda tutmak için hemşireler hastaları, proteinden zengin ve yüksek kalorili diyet almaları konusunda bilgilendirmelidir (15,16). Oral alım yetersiz, çok zahmetli veya yorucu hale geldiğinde veya aspirasyon riskine yol açarak güvenliği 
tehlikeye attığında, vücut ağırlığını stabilize etmek için alternatif beslenme yolları düşünülebilir. Bu yöntemler arasında ALS hastalarında en çok tercih edilen girişim perkütan endoskopik gastrostomi (PEG)dir (14-16).

\section{A ̆grı}

Ağrı, ALS'li hastaların \%57-72'sinde görülen fakat çoğu zaman ihmal edilen bir semptomdur. ALS hastalarının yaşadığ 1 kronik ağrının çoğu ALS'deki motor bozukluğun bir sonucu olarak ortaya çıkmaktadır (17). Ağrı primer olarak kramplar, spastisite ve nöropati şeklinde görlürken sekonder olarak nosiseptif ağrı şeklinde görülebilir. Ağrının lokalizasyonu genellikle ekstremiteler, boyun, sırt veya gövdedir. Ağrı, hastalığın ilk evrelerinde düşük bir görülme oranına sahip olsa bile hastalık ilerledikçe fonksiyon kaybının artmasıyla beraber daha şiddetli görülmektedir. Bu nedenle ağrının tedavisi ALS'de palyatif bakımın yönetimi açısından oldukça önemli olarak kabul edilmektedir (17). Ağrı yönetiminin temel amacı ağrının yarattığı rahatsızlığı gidermek ve ağrının kronikleşmesini önlemektir (17). Ağrının nedeni tanımlandıktan sonra hastalara özgü kişiselleştirilmiş tedavi planı olarak farmakolojik veya nonfarmakolojik yöntemler uygulanır. Hemşirelerin ağrı yönetiminde yapacakları ilk uygulama ideal ağrı değerlendirmesidir $(10,11,17)$. Daha sonra belirlenen tedavi planı hastaya uygulanır. Ağrı tedavisinde sıklıkla kullanılan farmakolojik ajanlar nonsteroid anti inflamatuar ilaçlar, opioid olmayan analjezikler, opioidler ve kas gevşeticilerdir (17) Hemşirelerin uygulamış oldukları ilaç tedavisinin etkinliğini değerlendirmeleri, tedavi sonuçlarını izlemeleri gelişebilecek tedavi komplikasyonlarına müdahale etmeleri ve kayıt tutmaları gerekmektedir (17) .

Spastisiteden kaynaklı ortaya çıkan ağrıların yönetimi için düzenli egzersiz, aktif veya pasif eklem hareket açıklığı egzersizleri konusunda hastalar teşvik edilmelidir (17). Bu yaklaşımlar ayrıca motor dejenearasyondan kaynaklanan sekonder ağrıyı tedavi etmek için de kullanılabilir (17). Örneğin, hemşire tarafından erken ağrı değerlendirilmesi yapılan hastalarda düzenli bir germe egzersizi ve eklem hareket açıklığ 1 egzersizleri programı omuz ağrısının ortaya çıkmasını önleyebilir (17).

Hastalarda hareket yeteneğinin azalmasına bağlı olarak ortaya çıkan ağrıların yönetmi için yardımcı cihazlar kullanılabilir. Özel yataklar ve destekleyici yastıkların kullanılması hastalara bu konuda yardımcı olacaktır. El ve ayak bileklerinde oluşan kontraktürlerden kaynaklı ağrıların önlenmesi için splint uygulamaları hasta için yararlı olacaktır. Düşmelerin ve yaralanmaların önlenmesi ve bunların yol açacağı ağrının oluşmaması için hemşirelerin hastaya ve bakıcısına güvenli transfer konusunda eğitim vermesi gerekmektedir. Hemşireler baston ve yürüteç gibi yardımcı cihazların kullanımıyla ilgili hastayı bilgilendirmelidir (17).

\section{Bağırsak ve Mesane İnkontinansı}

Kaslardaki atrofi ve hareketsizliğe bağlı olarak ALS'li hastaların en sık rastladığı sorunlardan biri bağırsak ve mesane inkontinansıdır (14). Hastalar belirli aralıklarla tuvalete götürülmeli (gündüzleri 2 saat arayla geceleri daha seyrek olmak üzere) ya da ördek, sürgü gibi araçlar olduğunca hastanın yanı başında veya kolay ulaşabileceği yerde bulundurulmalıdır (14). Hemşire hastanın yeterli sıvı almasını teşvik etmelidir, çünkü hastalar ve bakım verenler idrar inkontinansından korktukları için hastanın sıvı almasını kısıtlamış olabilirler (14). 


\section{İletişim}

Amyotrofik Lateral Skleroz hastalarının \%80-95'i konuşarak iletişim kurma yeteneklerinin kaybetmişlerdir (17). 2014 yılında Türkiye'de ALS-MNH (Amyotrofik Lateral Skleroz Motor Nöron Hastalığı) Derneği tarafından yürütülen "Yaşamak yetmez yaşatmak lazım" adlı çalışmadan elde edilen verilere göre, Türkiye'deki hastaların sadece \%14 ü ileri teknoloji kullanarak iletişim kurabilmektedir (18).

Dizartri ve iletişim yeteneğini kaybetme olasılığg, ALS'li insanlar için korkutucu semptomlardır. Dizartri ilerledikçe, düşük teknolojili (örn. Alfabe kartı) ve yüksek teknolojili (bilgisayar destekli) cihazlar gibi alternatif iletişim cihazlarına ihtiyaç duyulmaktadır. Yapılan çalışmalar alternatif iletişim cihazlarının kullanımının artmasıyla birlikte kişilerin yaşam kalitesinin de arttığını bildirmektedir. Göz hareketi kontrollü ekran klavyesinin son zamanlardaki gelişimi, herhangi bir uzuv fonksiyonu olmayan kişiler için iletişim sağlamaktadır. Hemşireler ALS hastalarını ve ailelerini bu konuda üretilen cihazlar hakkında bilgilendirebilirler (18-20). Destekleyici ve alternatif iletişim tekniklerinin kullanılmasında Sağlık Bakanlığı ve Sosyal Güvenlik Kurumunun desteğine ihtiyaç duyulmaktadır.

\section{SONUÇ}

Amyotrofik Lateral Skleroz remisyon veya alevlenme dönemleri olmaksızın ilerleyen bir hastalıktır (21). Hastalarda görülen semptomlar kalıcı sakatlıklara veya yaşamı tehdit eden nöromusküler solunum yetmezliklerine neden olmaktadır (21). Bu anlamda uzun süreli klinik izlem ve bakım gerektirir. Hemşireler, ALS yolculukları boyunca hastalara ve ailelere bütünsel bakım ve destek sağlamak için kilit konumda yer alırlar. Hemşirelerin, hasta ve bakım verenlere psikolojik destek sağlanması, semptom kontrolünün sağlanması, ihtiyaçları dahilinde eğitim verilmesi ve yaşam sonu bakımın hazırlanması gibi bir çok ana odak noktalarında rolleri vardır.

\section{Çıkar Çatışması}

Yazarlar arasında çıkar çatışması yoktur.

\section{KAYNAKLAR}

1. Handy, C. R., Krudy, C., Boulis, N., \& Federici, T. (2011) Pain in amyotrophic lateral sclerosis: a neglected aspect of disease. Neurology research international, (Electronic Journal) 6(s3):

$1-8$. https://www.ncbi.nlm.nih.gov/pmc/articles/PMC3135011/pdf/NRI2011-403808. (Erişim Tarihi: 20 Mart 2020).

2. Hulisz, D. (2018). Amyotrophic lateral sclerosis: disease state overview. Am J Manag Care, 24(15), 320-326.

3. Chiò, A., Mora, G., \& Lauria, G. (2017). Pain in amyotrophic lateral sclerosis. Lancet Neurol, 16(2), 144-157.

4. Mehta, P., Horton, K., Kasarskis, E. J., Tessaro, E., Eisenberg, M. S., Laird, S., et.al. (2017). CDC grand rounds: national amyotrophic lateral sclerosis (als) registry 1mpact, challenges, and future directions, US Department of Health and Human Services/Centers for Disease Control and Prevention, 66(50), 1379-1382. 
5. Wang, M. D., Little, J., Gomes, J., Cashman, N. R., \& Krewski, D. (2017). Identification of risk factors associated with onset and progression of amyotrophic lateral sclerosis using systematic review and meta-analysis. Neurotoxicology, (61), 101130.

6. Zarei, S., Carr, K., Reiley. L., Diaz K., Guerra O., Fernandez, P., et al. (2015). A comprehensive review of amyotrophic lateral sclerosis. Surgical Neurology International, 11(6)1, 171.

7. Hardiman, O., Berg, L. H., \& Kiernan, M. C. (2011). Clinical diagnosis and management of amyotrophic lateral sclerosis. Nat Rev Neurol. 7(11), 639-649.

8. Capozzella, A., Sacco, C., Chighine, A., Scala, B., Casale, T.,et al.(2014). Work related etiology of amyotrophic lateral sclerosis (ALS): a meta-analysis. Ann Ig. 26(5), 456472.

9. Bradley, W. G., Borenstein, A. R., Nelson, L. M., Codd G. A., Rosen B. E., Stommel E. A., et al.(2013). Is exposure to cyanobacteria an environmental risk factor for amyotrophic lateral sclerosis and other neurodegenerative diseases? Amyotroph Lateral Scler Frontotemporal Degener, 14(5-6), 325-333.

10. Jackson, C. E., McVey, A. L., Rudnicki, S., Dimachkie, M. M., \& Barohn, R. J. (2015). Symptom Management and End-of-Life Care in Amyotrophic Lateral Sclerosis. Neurol Clin. ,33(4),889-908.

11. Hobson, E. V., \& McDermott, C. J. (2016). Supportive and symptomatic management of amyotrophic lateral sclerosis. Nat Rev Neurol, 12(9), 526-538.

12. Ahmed, R. M., Newcombe, R. E., Piper, A. J., Lewis, S. J., Yee B. J., Kiernan B. C., et al. (2016). Sleep disorders and respiratory function in amyotrophic lateral sclerosis. Sleep Med Rev. (26), 33-42.

13. Pinto, S., \& Carvalho, Md. (2014). Breathing new life into treatment advances for respiratory failure in amyotrophic lateral sclerosis patients. Neurodegenerative Disease Management, 4(1), 83-102.

14. Alankaya, N. (2012). Amiyotrofik lateral skleroz ve hemşirelik yönetimi. Anadolu Hemşirelik ve Sağllk Bilimleri Dergisi, 2(15), 159-152.

15. Roche, J. C., Rojas-Garcia, R., Scott, K. M., Scotton, W., Ellis C. E., Burman, R. ,et al. (2012). A proposed staging system for amyotrophic lateral sclerosis. Brain, 135(3), 847852.

16. Özcan, F., Kaya, A., \& Yayla, M. (2016). Amyotrofik lateral skleroz hastalığı ve aile hekiminin rolü. Celal Bayar Üniversitesi Sağllk Bilimleri Enstitüsü Dergisi, 3 (3) , 431435.

17. Delpont, B., Beauvais, K., Jacquin-Piques, A., Alavoine, V., Rault, P., Blanc-Labarre, C., et.al. (2018). Clinicalfeatures of pain in amyotrophiclateralsclerosis: A clinicalchallenge. Revue Neurologique,175(1-2), 11-15.

18. Kaya, A., Dik, A., Tülek, Z., Alankaya, N., Özakgül, A., Ünalan, P., \& İdrisoğlu, H. A. (2015). Amyotrofik Lateral Sklerozlu (ALS) Hastalara Evde Bakım Projesi:"Yaşamak Yetmez, Yaşatmak Da Lazım”.

19. Caligari, M., Godi, M., Guglielmetti, S., Franchignoni, F., \& Nardone, A. (2013). Eye tracking communication devices in amyotrophic lateral sclerosis: impact on disability and quality of life. Amyotroph Lateral Scler Frontotemporal Degener, 14(7-8), 546552.

20. Londral, A., Pinto, A., Pinto, S., Azevedo, L., \& De Carvalho, M.(2015). Quality of life in amyotrophic lateral sclerosis patients and caregivers: Impact of assistive communication from early stages. Muscle Nerve. 2(6), 933-941.

21. Vacca, V. M. Jr. (2020). Amyotrophic lateral sclerosis: Nursing care and considerations. Nursing,50(6), 32-39. 